\title{
An Easy and Efficient Method to Functionalize Titanium Dioxide Nanoparticles with Maleic Anhydride
}

\author{
Pável C. Hernández Del Castillo1 ${ }^{*}$, Saúl Robles Manuel2, Facundo Ruiz ${ }^{2,3}$ \\ ${ }^{1}$ Doctorado Institucional en Ingeniería y Ciencia de Materiales, UASLP, San Luis Potosí, México \\ ${ }^{2}$ Facultad de Ciencias, UASLP, San Luis Potosí, México \\ ${ }^{3}$ Centro de Investigación en Materiales Avanzados (CIMAV), Chihuahua, México \\ Email: "paveldelcastillo@gmail.com
}

Received 5 May 2014; revised 5 June 2014; accepted 5 July 2014

Copyright (C) 2014 by authors and Scientific Research Publishing Inc.

This work is licensed under the Creative Commons Attribution International License (CC BY). http://creativecommons.org/licenses/by/4.0/

(c) $\underset{\mathrm{EY}}{\mathrm{i}}$ Open Access

\section{Abstract}

In this work, titanium dioxide $\left(\mathrm{TiO}_{2}\right)$ nanoparticles were functionalized with maleic anhydride (MA), using a non-polar (toluene) and polar protic (ethanol) solvents. The concentrations of MA in the reaction were varied to obtain the desired degree of functionalization. The samples were characterized with Fourier Transform Infrared Spectroscopy (FTIR), Diffuse Reflectance UV-Vis Spectroscopy (DRS), Thermal Analysis (TGA-DTA) and Nitrogen Adsorption (BET). The physical adsorption of organic molecules was eliminated by washing a number of times in water. Chemical stability between solid-organic phases was confirmed by TOC and thermal analysis. FT-IR and DRS results clearly show the chemical adsorption of $\mathrm{MA}$ on the $\mathrm{TiO}_{2}$. The UV-Vis spectroscopy is claimed to be a suitable technique to determine the achievement of $\mathrm{TiO}_{2}$ functionalization. Two different adsorptions geometries of MA were proposed. The presence of MA on the surface $\mathrm{TiO}_{2}$ increases the band gap. These results imply that $\mathrm{TiO}_{2}$ can be excited with less energy and increase the absorption of light in the visible region. The effectiveness of the functionalized nanoparticles to interact with organic materials is currently being studied with the intention of applying them in the energy and environmental sanitation fields.

\section{Keywords}

$\mathrm{TiO}_{2}$ Nanoparticles, Functionalization, Maleic Anhydride, Sensitization, Adsorption on Solid

\footnotetext{
${ }^{*}$ Corresponding author.
}

How to cite this paper: Del Castillo, P.C.H., Manuel, S.R. and Ruiz, F. (2014) An Easy and Efficient Method to Functionalize Titanium Dioxide Nanoparticles with Maleic Anhydride. Soft Nanoscience Letters, 4, 53-62. 


\section{Introduction}

In the study of nanomaterials, the metal oxides have been of great interest in various fields such as hybrid materials, photocatalysis, solar cells and functionalized membranes. The $\mathrm{TiO}_{2}$ only absorb $4 \%$ of sunlight [1]. However the absorption range in the $\mathrm{TiO}_{2}$ is shifted to the visible light region allowing the possibility of their application in many scopes e.g. purification and disinfection of water, solar photocatalysis and cells. Several attempts to enhance the ability of $\mathrm{TiO}_{2}$ to capture photons have been reported by Chen et al. [2] and Takai et al. [3]. Some of the known methods of sensitizing or functionalizing the surface of materials are etching, doping, ion implantation, vapor phase deposition, organic molecules anchoring and photo-deposition of metals. The activity of $\mathrm{TiO}_{2}$ in visible light region have been achieved by anchoring organic compounds [4]-[6], metal ions doping [7]-[10], or nitrogen [11]-[13] and introducing [1] [11] [14].

The extension of the $\mathrm{TiO}_{2}$ absorption limit to visible light region due to the growth of oxides on functionalized graphene sheets with Fe have been reported by Farhangi et al. [15]. A sulfanilic acid-modified P25 showed absorption in the visible light region [6]. The surface modification of $\mathrm{TiO}_{2}$ nanoparticles (Degussa P25) with a $\mathrm{C}_{60}$ derivative, $\mathrm{C}_{60}(\mathrm{CHCOOH})_{2}$ allows the sensitization to the visible light region and therefore led to the reduction of $\mathrm{Cr}(\mathrm{VI})$ in the visible region [5]. The surface modification of $\mathrm{TiO}_{2}$ nanoparticles with self-prepared camphorsulfonic acid-doped polyaniline using tetrahydrofuran (THF) as solvent [16] was reported. The characterization of functionalized nanoparticles is strongly supported by diffuse reflectance UV-Vis spectroscopy. The absorbtion of light in the visible light region increased as the amount of polyaniline increases. This indicates that there is a suitable sensitization of $\mathrm{TiO}_{2}$. In addition, it is necessary to know the physicochemical properties of the surface of the solid. Multidentate binding gives high stability to the anchored compounds on the surface of oxides [17].

The process of photosensitization induces a rapid transfer of electrons into the conduction band of $\mathrm{TiO}_{2}$ towards the visible light range. As a result the absorption of photons by the solid is increased. In general, the phenomenon consists in the excitation of $\pi$ bonds of the organic molecule by photons. The electron is excited to a higher energy level as the consequence of charge transferred to the conduction band of the solid [18]. The absorption capacity of solids in the visible range usually increases as the complexity of the anchored molecules increase. The number of photons acceptor centers and the molar extinction coefficient increase with the molecular complexity of the compound.

MA may serve as a "seed molecule" capable of anchoring to other organic molecule [19]. Also, it is an important compound for the synthesis of several chemical products. Furthermore, it is used to produce resin components. Maleic anhydride $\left(\mathrm{C}_{4} \mathrm{H}_{2} \mathrm{O}_{3}, \mathrm{MA}\right)$ is a dicarboxylic acid that is widely used in the production of polymers, agricultural chemicals, pharmaceuticals, additives for lubricants, surfactants and functionalizing materials. Dicarboxylic acids have biodegradable and biocompatible amino acids that make them an excellent choice for use as compatibilizing agents. Therefore, understanding the behavior of MA on the surface of $\mathrm{TiO}_{2}$ is of great interest in the field of catalysis and semiconductors. These studies can be applied to the development of solar cells and surface passivation. There are few investigations that have been conducted on the study of the adsorption of dicarboxylic acids on the surface of $\mathrm{TiO}_{2}$.

Studies on the interaction between the surface of solids and organic acids have been made. However, only a few investigations about surface modification of oxides with MA had been done [19]-[22]. The decomposition of MA on surface of $\mathrm{TiO}_{2}$ single crystal was studied and reported the anchor of the molecule on the planes (101), (100) and (001) of anatase [19]. Mainly based on X ray-photoelectron spectroscopy (XPS) results, the last authors have concluded that the plane (001) were presented two types of oxygen on the surface, possibly due to a not dissociative adsorption.

These results indicate the presence of four equivalents oxygen on the surface. This explains why the behavior of the MA on the surface of $\mathrm{TiO}_{2}$ is similar to a carboxyl acid. This adsorption reaction could be done via a nucleophilic addition mechanism. The organic molecule should contribute three oxygen atoms and the fourth one comes from the surface of the $\mathrm{TiO}_{2}$. Furthermore, other researchers have found similar conclusions when the adsorption of $\mathrm{MA}$ on $\mathrm{TiO}_{2}$ (001) is in a single crystal, e.g. rutile [22]. A dissociative adsorption was suggested to be the most stable configuration of $\mathrm{MA} / \mathrm{TiO}_{2}$. The molecules were suggested to adsorb on the $\mathrm{Ti}_{5} \mathrm{C}^{4+}$ ions. These kinds of $\mathrm{Ti}^{4+}$ ions are normally presented on the surface of $\mathrm{TiO}_{2}$ (rutile and anatase crystalline structures), which may interact with the oxygen [23]-[27].

The procedure reported to anchor MA on solids, imply the use of highly specialized methodologies such as, ultra high vacuum system [28]-[30]. In this work, a simple method has been developed to functionalize the surface of $\mathrm{TiO}_{2}$ nanoparticles. The method of functionalization is done in two different solvents. The DRUV-Vis 
spectroscopy is proposed as a qualitative method to determine the functionalization of $\mathrm{TiO}_{2}$ nanoparticles. This research reports the adsorption geometry of the anchored molecule and the quantity of surface functionalized. The stability of the chemical adsorption is evident in the results of several analyses.

\section{Experimental}

\subsection{Materials}

The maleic anhydride (MA) was supplied by Sigma-Aldrich, 99\% pure. The toluene used as solvent was brought to CTR Scientific, $99.8 \%$ pure $(\mathrm{Mw}=92.14 \mathrm{~g} / \mathrm{mol})$. Titanium dioxide $\left(\mathrm{TiO}_{2}\right)$ nanoparticles were purchased from Degussa (P-25) and were used as received. The characteristics given for supplier are: i) the particle mean size of $\sim 21 \mathrm{~nm}$, ii) surface area of $50 \mathrm{~m}^{2} \cdot \mathrm{g}^{-1}$ and iii) the composition is a mixture of anatase $(\sim 80 \%)$ and rutile ( 20\%).

\subsection{Synthesis of Functionalized $\mathrm{TiO}_{2}$}

$\mathrm{TiO}_{2}$ nanoparticles and MA were employed as raw materials. Two solvents (protic and non-protic) were used as reaction media, according to the follow procedure: $1 \mathrm{~g}$ of $\mathrm{TiO}_{2}$ was dispersed in $200 \mathrm{ml}$ of ethanol (ET) or toluene (TO), then the mixture was stirred and heated up to $50^{\circ} \mathrm{C}$ or $80^{\circ} \mathrm{C}$ respectively, depending of solvent. At this point, MA was dissolved in $10 \mathrm{ml}$ of solvent, added slowly. The weight ratio $\mathrm{TiO}_{2}$ : $\mathrm{MA}$ was varied to obtain different grades of functionalization. The concentrations were: 1:0.5 (1TiMA) and 1:5 (2TiMA). The reaction was maintained in constant reflux during enough time to react, e.g. 4.5 hours. Then, the solvent was separated by centrifugation to recover the functionalized nanoparticles. The product was washed with water and dried to obtain the 1TiMA and 2TiMA samples.

\subsection{Characterization}

The thermal behavior of modified $\mathrm{TiO}_{2}$ was determined by TGA-DTA on a SDT Q600 of TA with a heating rate of $10^{\circ} \mathrm{C} \cdot \mathrm{min}^{-1}$ in the range of temperature from $25^{\circ} \mathrm{C}$ to $700^{\circ} \mathrm{C}$. The FTIR spectra were recorded using a Nicolet 670 spectrometer. Diffuse reflectance spectra were collected in a S2000 UV-Vis spectrophotometer from Ocean Optics. The crystalline structure of $\mathrm{TiO}_{2}$ was probed by XRD in a range $\left(10^{\circ}\right.$ to $\left.80^{\circ}\right)$ of $2 \theta$ with a speed recording at $2^{\circ} \mathrm{min}^{-1}$ and step of $0.02^{\circ}$. In addition, the waste water from the washes was measured by TOC (VCPH-CPN, Shimadzu co.) to determine the total organic carbon amount.

\section{Results and Discussion}

The physical adsorption of MA was dismissed and supported by the TOC and TGA results. In general, the samples were washed with $100 \mathrm{~mL}$ of water at different times. The TOC determined for each volume recovered after the removal of solids by filtration. The TOC values in wastewaters were performed after using $300 \mathrm{~mL}$, which was the minimum volume used to wash the nanoparticles. In the consecutives experiments (Figure 1). The TGA shows (Figure 2) the weight loss before and after the washes, proving the efficiency of process in the elimination of physical adsorbed molecules.

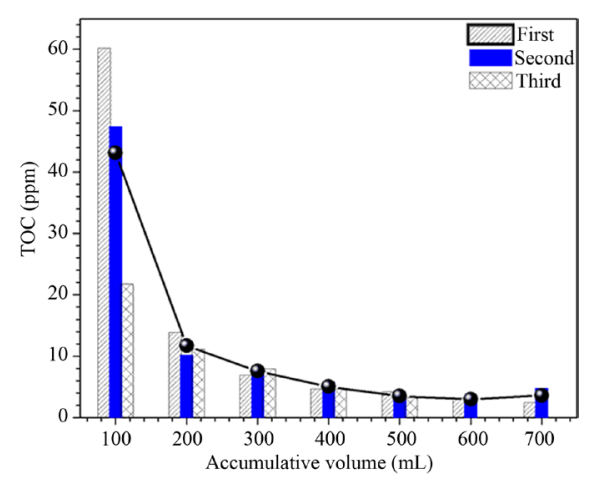

Figure 1. TOC analysis of residual water used in the washes of the 2TiMA-ET sample. 


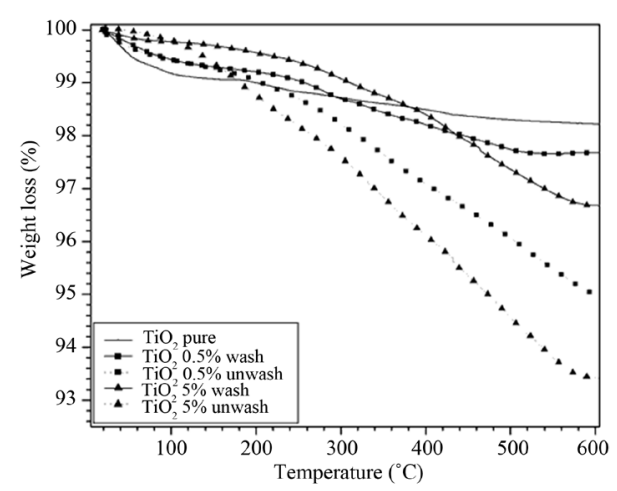

Figure 2. TGA analysis of 1TiMA-ET and 2TiMA-ET samples.

The Bet results showed no difference. The area of modified samples was $50 \mathrm{~m}^{2} \cdot \mathrm{g}^{-1}$. This value was also observed for the pristine sample. This might suggest the small surface occupied by the organic onto $\mathrm{TiO}_{2}$ nanoparticles. The XRD pattern did not present other different phases than the observed in the pristine sample (Figure 3).

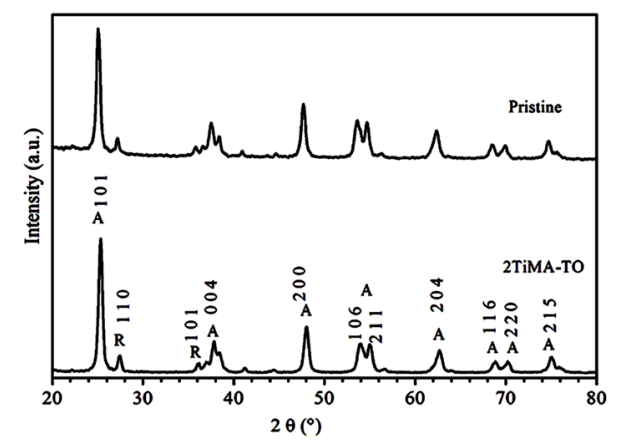

Figure 3. XRD pattern of $\mathrm{TiO}_{2}$ and 2TiMA-TO samples.

Figure 4, shows the FTIR spectra of the different dried samples (e.g. $\left.120^{\circ} \mathrm{C}\right)$. The asymmetric $\left(1869 \mathrm{~cm}^{-1}\right)$ and symmetric $\left(1783 \mathrm{~cm}^{-1}\right) \mathrm{C}=\mathrm{O}$ vibrations of MA molecule were not observed. Two peaks, one at $1714 \mathrm{~cm}^{-1}$ and the other at $1696 \mathrm{~cm}^{-1}$, were found. The vibrational band of 2TiMA-TO is composed for a maximum and a shoulder at the same wave number given. These peaks correspond to the asymmetric vibrations of carboxylate ions $\left(\mathrm{COO}^{-}\right)$. The symmetric vibrations of $\mathrm{COO}^{-}$together with the $\mathrm{C}=\mathrm{C}$ stretching were deconvoluted in the band centered at $1570 \mathrm{~cm}^{-1}$. Mainly due to the difficulty of identifying the vibrational bands centered between $1800-1640 \mathrm{~cm}^{-1}$ wich are mainly composed of two peaks were deconvoluted. The fit was done by Lorentzian functions is a similar method used to obtain the XPS spectra [31] [32]. The deconvolutions in two and three components were attempted. The same procedure was applied for the broad band centered at $1570 \mathrm{~cm}^{-1}$.

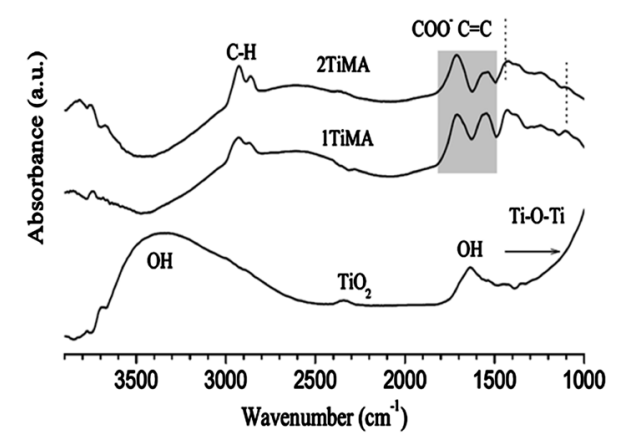

Figure 4. FT-IR spectra of $\mathrm{TiO}_{2}$, 1TiMA and 2TiMA in the range 4000 to $1000 \mathrm{~cm}^{-1}$. 
The assumption made for the region $1800-1640 \mathrm{~cm}^{-1}$ was confirmed after of the deconvolutions, inserted in the Figure 5. The best fit presented two peaks around $1714 \mathrm{~cm}^{-1}$ and $1696 \mathrm{~cm}^{-1}$. The second band centered between $1600-1400 \mathrm{~cm}^{-1}$ was fitted better using three components. This revealed the contribution of three different peaks 1546, 1514 (assigned to two different $\gamma_{\mathrm{s}}\left(\mathrm{COO}^{-}\right)$) and $1584 \mathrm{~cm}^{-1}$. The last peak correspond to the stretching $\mathrm{C}=\mathrm{C}$ which has a shift of $10 \mathrm{~cm}^{-1}$ compared with the MA molecule [33]-[35]. The same vibration is observed in the maleic acid at $1587 \mathrm{~cm}^{-1}$ [33]. The small shift is justified because there is no direct interaction between the organic bond and the solid surface. The bands corresponding to the C-O-Ti (e.g. 1160 and 1096 $\mathrm{cm}^{-1}$ ) were observed [36] [37]. A well-defined band at $1220 \mathrm{~cm}^{-1}$ was assigned to the bend vibration of C-H bond [37].

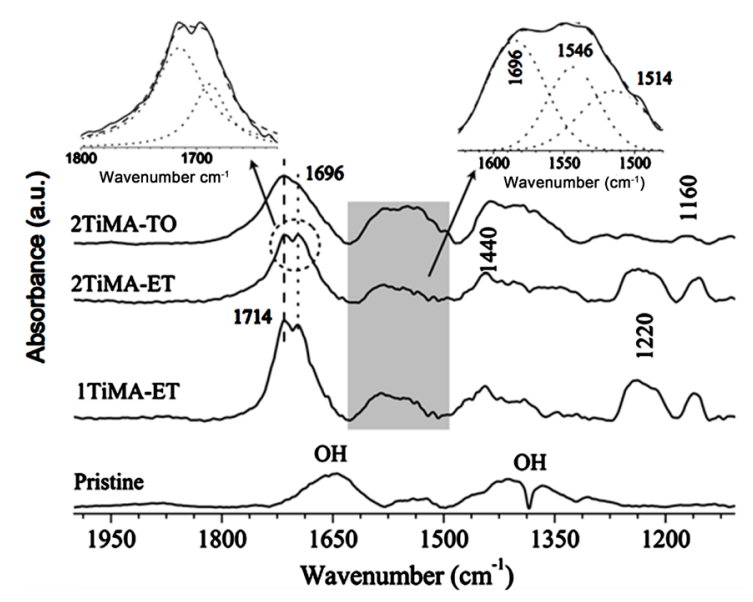

Figure 5. FT-IR spectra of pristine $\mathrm{TiO}_{2}, 1 \mathrm{TiMA}$ and 2TiMA in the range 2000 to $1100 \mathrm{~cm}^{-1}$.

The difference $\left(\Delta \gamma_{\text {as-s }}\right)$ between the asymmetric $\left(\gamma_{\text {as }}\right)$ and the symmetric $\left(\gamma_{s}\right)$ stretch vibrations of carboxylic acids are molecules that define the binding arrangement of organic on the surface of solid. Commonly, the difference is $350-500 \mathrm{~cm}^{-1}$ for monodentate, $150-180 \mathrm{~cm}^{-1}$ for bidentate bridging and $60-100 \mathrm{~cm}^{-1}$ for bidentate chelating. Since the $\Delta \gamma_{\mathrm{a}-\mathrm{s}}$ of distinct assignations done fell between 200 and $150 \mathrm{~cm}^{-1}$ is assumed that the MA molecules are mainly bonded in two different bidentate bridging arrangements on the surface of $\mathrm{TiO}_{2}($ Figure 6(A) and Figure 6(B)). Furthermore, the band at $1160 \mathrm{~cm}^{-1}$ assigned to C-O-Ti support the assumption that bidentate binding modes are occurring. The stretching vibration of C-O-Ti at $1140 \mathrm{~cm}^{-1}$ has been related to bidentated propoxy species on surfaces of $\mathrm{TiO}_{2}$ [36] [37]. The deconvolution performed to estimate the percentage of each component (vibration) of the peaks. Based in the results of the band corresponding to $\gamma_{\text {as }}$, shown that on sample 2TiMA-ET occurs a different fraction of bidentated peaks of 1714/696 (2.4), compared with that (11.7) in the 2TiMA-TO.<smiles>CC1CCC(=O)OC1=O</smiles>

B<smiles></smiles><smiles>O=C1OC(=O)C2CCCC(C2)O1</smiles>

C

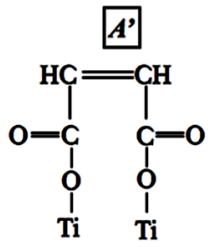<smiles>CCCOC1CC2COC(O2)O1</smiles>

Figure 6. Possible adsorption forms of MA on surface of $\mathrm{TiO}_{2}$ : $\mathrm{A}$ and $\mathrm{A}^{\prime}$ ) monodentate, B) Bidentate bridgings and C) Bidentate chelating. 
The two binding modes proposed imply a ring opening. Indeed, these two absorption modes have already been reported by different authors (Johansson et al. [19] and Wilson et al. [22]). Johansson et al. [19] found that the only possibility to correlate the observation of one peak of oxygen $(\mathrm{O} 1 \mathrm{~s}-532 \mathrm{eV})$ on the XPS spectra of MA anchored on $\mathrm{TiO}_{2}$, should be a bidentate bridging [19]. The result is supported by the appearance of only two different carbons signals. Indeed, the planes (101) and (100) of single crystal anatase present this behavior, while the (001) surface showed two peaks of O1s (532 and $534.5 \mathrm{eV}$ ). The first one is the more reactive [40]. Nevertheless, in the three surfaces only two kinds of carbons were detected, one for carbonyl and the other for olefinic group at 289 and $286 \mathrm{eV}$ respectively [19]. Other authors have had similar conclusions for (001) rutile surface [22]. Based on the thermal programmed desorption (TPD) studies and simulations results, a monodentate binding (see Figure 1(a)) was suggested for the anchoring of $\mathrm{MA}$ on $\mathrm{TiO}_{2}(001)$ surface [22]. However, this proposition agrees with observations in a study involving $\mathrm{MA}$ and single crystals of $\mathrm{TiO}_{2}$, because two types of oxygen and carbons could be present on this configuration [19]. Hence, it was very possible for both adsorption modes to be carried out. The $\mathrm{TiO}_{2}$ (e.g. Degussa P25) here used consist of both crystalline structures but mainly anatase. The (101) surface is the most common surface of anatase nanoparticles [38] [39]. Therefore, the most exposed during our experiments. It must be assumed that the main adsorption mode is bidentate binding. This kind of adsorption has been observed in the behavior of monocarboxylic acid and others organic molecules [40]. Lopez et al. [20] reported the adsorption of MA on silica as bidentate geometry throughout the Si-C bounds.

The thermal behavior of 2TiMA-TO is described in the Figure 7. Two important weight losses were observed: the first loss from $45^{\circ} \mathrm{C}$ to $220^{\circ} \mathrm{C}(1.17 \%)$ is attributed to the elimination of solvent used in the reaction; the rest is water adsorbed and probably lost of unreacted MA [41]. The endothermic peak observed in DTA curve at the same range is typical behavior of desorption process [42]. The second weight loss (4.07\%) coincided with a broad exothermal effect from $230^{\circ} \mathrm{C}$ to $580^{\circ} \mathrm{C}$ on the DTA curve. This larger weight loss was attributed to the decomposition and desorption of the anchored MA. Exothermic peaks related to the decomposition of pure copper and zinc maleate hydrated between $210^{\circ} \mathrm{C}-320^{\circ} \mathrm{C}$ and $250^{\circ} \mathrm{C}-450^{\circ} \mathrm{C}$ respectively were observed [41]. The peaks had been attributed to the decomposition of the maleate in different steps. They observed the main decomposition-desorption of $\mathrm{MA}$ on $\mathrm{TiO}_{2}$ occurring between $280^{\circ} \mathrm{C}-470^{\circ} \mathrm{C}$. The carbonates-like structure formed from the decomposition of MA desorbs after $470^{\circ} \mathrm{C}$. It must be pointed out that after $500^{\circ} \mathrm{C}$ desorption of molecules such as acetylene and $\mathrm{CO}_{2}$ have been detected [9] [29]. The samples 1TiMA-TO and those prepared using ethanol present the same behavior. In all samples prepared, the maximum weight loss was around $4.0 \%$. This is due to saturation limit or charge accepted on the surface of $\mathrm{TiO}_{2}$.

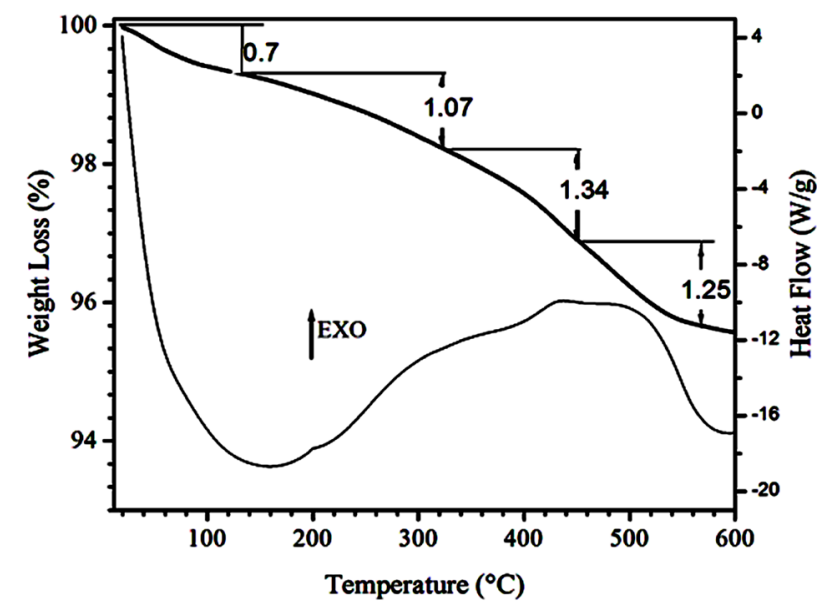

Figure 7. Thermal analysis of 2TiMA-TO sample.

The UV-Vis spectra of the samples were compared in the Figure 8. A noticeable shift in the band gap could be observed. Indeed, the values decreased by 0.26 and $0.45 \mathrm{eV}$ with respect to the pristine sample for 1TiMA-ET and 2TiMA-ET respectively, due to the increase of MA concentration on the surface. The same tendency was observed for the samples prepared with toluene, e.g. the difference decrease from 0.38 to 0.28 as the concentration of MA was increased. The MA presence on $\mathrm{TiO}_{2}$ surface reduced the band gap and increased the 
ability to absorb visible light. The bare sample did not present absorption after $400 \mathrm{~nm}$. Figure 9 describes the qualitative differences between the functionalized and pristine samples. These results confirm an interaction between the MA and the surface of $\mathrm{TiO}_{2}$, when there is an excitation of electrons by photons. Mu et al. (2010) observed the same phenomenon due to the close interaction of $\mathrm{C}_{60}(\mathrm{CHOOH})_{2}$ on the $\mathrm{TiO}_{2}$. A similar observation was made by Farhangi et al. [15] in a study about Fe doped with titania nanowires. The integrated area under the curves between 400 and $500 \mathrm{~nm}$ changed from 17.72 to $53.75 \mathrm{u}^{2}$ for pristine and 2TiMA-ET, respectively. The 2TiMA-TO sample has $52.58 \mathrm{u}^{2}$ under the curve. This result implies that $\mathrm{TiO}_{2}$ can be excited with less energy, extending the known light absorption ability of $\mathrm{TiO}_{2}$ to the visible light range due to the surface modified.

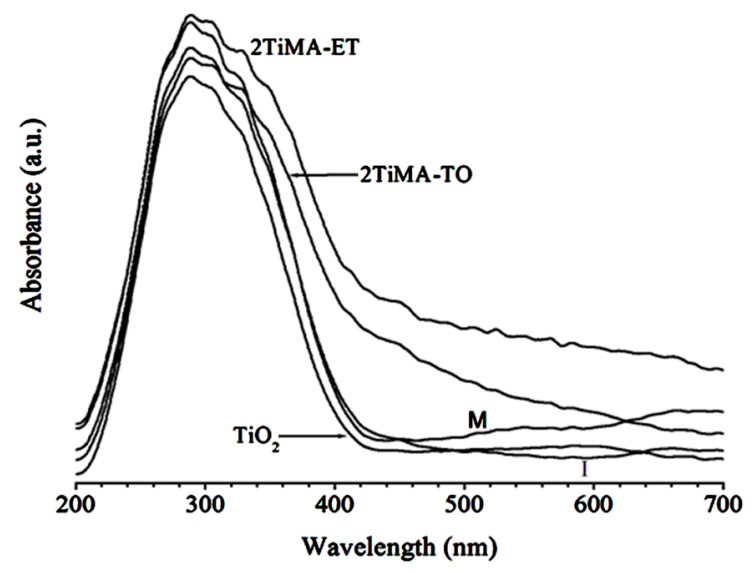

Figure 8. Diffuse Reflectance UV-Vis spectra of pristine $\mathrm{TiO}_{2}$, physical mixture (M), impregnated (I), 2TiMA-TO and 2TiMA-ET samples.

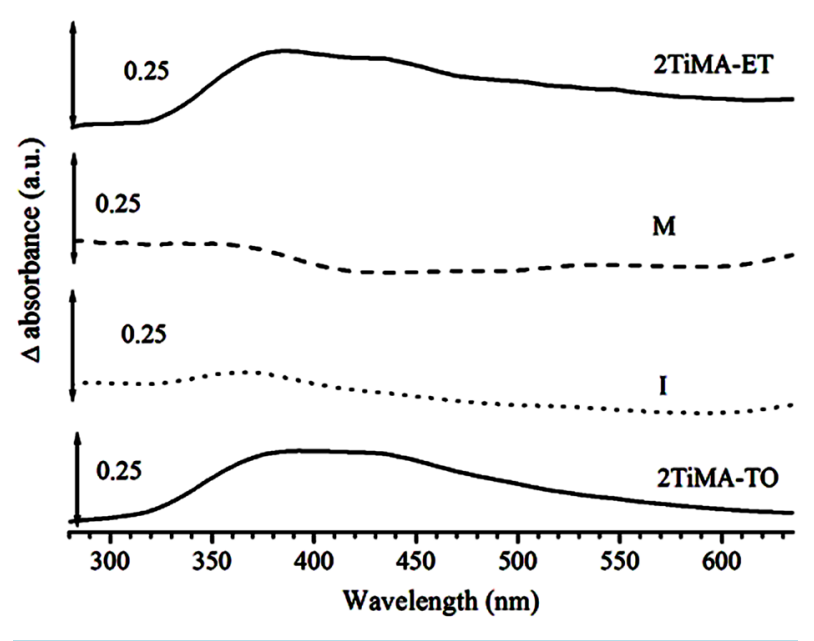

Figure 9. Comparison of the absorption on the visible light of 2TiMA-ET, Physical mixture (M), Impregnation reaction (I) and 2TiMA-TO samples.

The absorption of MA in the visible light region has never been reported or measured. In this research, it was found that the absorption of the functionalized samples occurs at waves lengths that are close to $400 \mathrm{~nm}$. $\mathrm{TiO}_{2}$ absorbs light up to $400 \mathrm{~nm}$ while maleic and fumaric acids absorb at 204 and $210 \mathrm{~nm}$ respectively. These do not absorb visible light. The adsorption presented in the functionalized samples is attributed to the synergy between the organic molecule and the surface of solid [43]. The presence of a double bond exposed to light can absorb photons that are able to excite the electrons of the $\mathrm{COO}^{-}$bond and transfer them to the conduction band (CB) of the $\mathrm{TiO}_{2}$. This implies that the $\mathrm{CB}$ of $\mathrm{TiO}_{2}$ interacts quite well with the $\pi$ orbital of the double bond of the organic compound, thus reducing the band gap (Figure 10) [44]. 


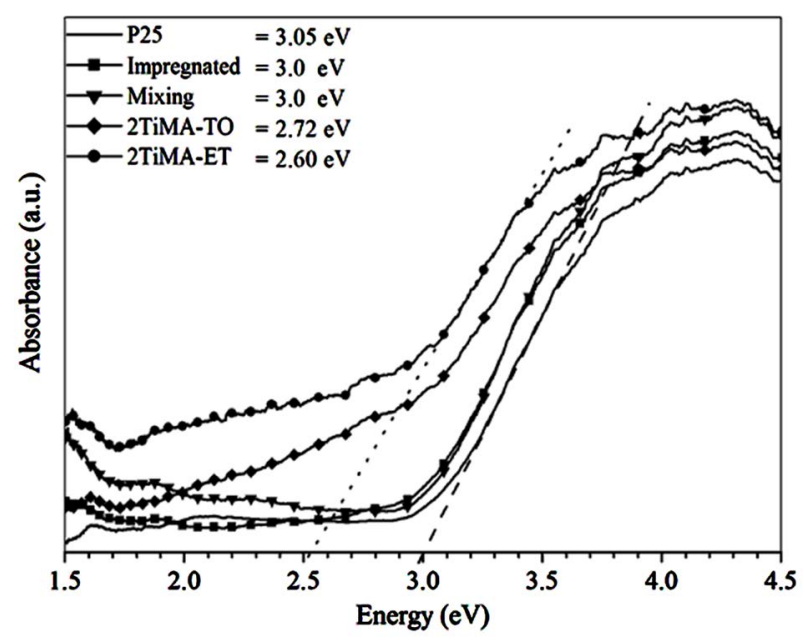

Figure 10. Band gap calculations for $\mathrm{TiO}_{2}$, impregnated, physical mixture, 2TiMA-TO and 2TiMA-ET samples.

\section{Conclusion}

The MA has been successfully chemically adsorbed on the surface of $\mathrm{TiO}_{2}$ using two different solvents as a reaction media, e.g. ethanol and toluene. The assumption is supported by TOC, TGA-DTA, FTIR and DR-UVVis. The last characterization technique revealed a direct interaction between the organic molecule and inorganic nanoparticle. This implies that functionalized $\mathrm{TiO}_{2}$ can be excited with less energy, extending the known effectiveness of $\mathrm{TiO}_{2}$ towards the visible light range as a result of the modified surface. The band gap shows a shift of $\sim 2.60 \mathrm{eV}$ (visible light region) in the 2TiMA-ET sample prepared with $5 \% \mathrm{wt}$ of MA per gram of $\mathrm{TiO}_{2}$ in ethanol. The spectroscopy studies exhibit that the MA behaves as a carboxyl acid which is adsorbed in form of carboxylates on the $\mathrm{TiO}_{2}$ surface. The main adsorption mode presented was a bidentate binding form (Figure 6(B) and Figure 6(C)). The chemical stability of the solid-organic phase is clearly seen after applying a series of washes with mechanical agitation to discard physical adsorption.

\section{Acknowledgements}

The authors are grateful to Ph.D. Octavio Domínguez Espinos and MSc. Martha Lomelí Pacheco for the use of the FTIR method. The authors also appreciate the support of CONACYT (Consejo Nacional de Ciencia y Tecnología) in this research.

\section{References}

[1] Rengifo, H.J.A., Mielczarski, E., Mielczarski, J., Castillo, N.C., Kiwi, J. and Pulgarin, C. (2008) Escherichia Coli Inactivation by N, S Co-Doped Commercial $\mathrm{TiO}_{2}$ Powders Under UV and Visible Light. Applied Catalysis B, 84, 448-456. http://dx.doi.org/10.1016/j.apcatb.2008.04.030

[2] Chen, D., Huang, F., Cheng, Y.B. and Caruso, R.A. (2009) Mesoporous Anatase $\mathrm{TiO}_{2}$ Beads with High Surface Areas and Controllable Pore Sizes: A Superior Candidate for High-Performance Dye-Sensitized Solar Cells. Advanced Materials, 21, 2206-2210. http://dx.doi.org/10.1002/adma.200802603

[3] Takai, A. and Kamat, P.V. (2005) Capture, Store, and Discharge. Shuttling Photogenerated Electrons Across TiO $\mathrm{A}_{2}-\mathrm{Sil}-$ ver Interface. ACSnano, 5, 7369-7376. http://dx.doi.org/10.1021/nn202294b

[4] Lucarelli, L., Nadtochenko, V. and Kiwi, J. (2000) Environmental Photochemistry: Quantitative Adsorption and FTIR Studies During the $\mathrm{TiO}_{2}$-Photocatalyzed Degradation of Orange II. Langmuir, 16, 1102-1108. http://dx.doi.org/10.1021/la990272j

[5] Mu, S., Long, Y., Kang, S.Z. and Mu, J. (2010) Surface Modification of TiO2 Nanoparticles with a C60 Derivative and Enhanced Photocatalytic Activity for the Reduction of Aqueous Cr(VI) Ions. Catalysis Communications, 11, 741-744. http://dx.doi.org/10.1016/j.catcom.2010.02.006

[6] Guo, H., Lin, K., Zheng, Z., Xiao, F. and Li, S. (2012) Sulfanilic Acid-Modified P25 TiO 2 Nanoparticles with Improved Photocatalytic Degradation on Congo Red Under Visible Light. Dyes and Pigments, 92, 1278-1284. 
http://dx.doi.org/10.1016/j.dyepig.2011.09.004

[7] Anpo, M., Dohshi, S., Kitano, M., Hu, Y., Takeuchi, M. and Matsuoka, M. (2005) The Preparation and Characterization of Highly Efficient Titanium Oxide-Based Photo Functional Materials. Annual Review of Materials Research, 35, 1-27. http://dx.doi.org/10.1146/annurev.matsci.35.100303.121340

[8] Rodríguez-González, V., Zanella, R., del Angel, G. and Gomez, R. (2008) MTBE Visible-Light Photocatalytic Decomposition Over $\mathrm{Au} / \mathrm{TiO}_{2}$ and $\mathrm{Au} / \mathrm{TiO}_{2}-\mathrm{Al}_{2} \mathrm{O}_{3}$ Sol-Gel Prepared Catalysts. Journal of Molecular Catalysis A, 281, 93-98. http://dx.doi.org/10.1016/j.molcata.2007.07.009

[9] Ren, F.J., Ling, Y.H. and Feng, J.Y. (2010) The Role of W Doping in Response of Hydrogen Sensors Based on MAO Titania Films. Applied Surface Science, 256, 3735-3739. http://dx.doi.org/10.1016/j.apsusc.2010.01.015

[10] Kim, T.H., Rodríguez-González, V., Gyawali, G., Cho, S.H., Sekino, T. and Lee, S.W. (2012) Synthesis of Solar Light Responsive Fe, $\mathrm{N} \mathrm{Co-Doped} \mathrm{TiO}_{2}$ Photocatalyst by Sonochemical Method. Catalysis Today, 212, 75-80. http://dx.doi.org/10.1016/j.cattod.2012.09.014

[11] Asahi, R., Morikawa, T., Ohwaki, T., Aoki, A. and Taga, Y. (2001) Visible-Light Photocatalysis in Nitrogen-Doped Titanium Oxides. Science, 293, 269-271. http://dx.doi.org/10.1126/science.1061051

[12] Zhang, Z., Wang, X., Long, J., Gu, Q., Ding, Z. and Fu, X. (2010) Nitrogen-Doped Titatium Dioxide Visible Light Photocatalyst: Spectroscopic Identification of Photoactive Centes. Journal of Catalysis, 276, 201-214. http://dx.doi.org/10.1016/j.jcat.2010.07.033

[13] Veréb, G., Ambrus, Z., Pap, Z., Kmetiko, Á., Dombi, A., Danciu, V., Cheesman, A. and Mogyorósi, K. (2011) Comparative Study on UV and Visible Light Sensitive Bare and Doped Titanium Dioxide Photocatalysts for the Decomposition of Environmental Pollutants in Water. Applied Catalysis B, 110, 25-32.

[14] Di Valentin, C., Pacchioni, G. and Selloni, A. (2005) Theory of Carbon Doping of Titanium Dioxide. Chemistry of Materials, 17, 6656-6665. http://dx.doi.org/10.1021/cm051921h

[15] Farhangi, N., Chowdhury, R.R., Medina-Gonzalez, Y., Ray, M.B. and Charpentier, P.A. (2011) Visible Light Active Fe Doped $\mathrm{TiO}_{2}$ Nanowires Grown on Graphene Using Supercritical $\mathrm{CO}_{2}$. Applied Catalysis B, 110, 25-32. http://dx.doi.org/10.1016/j.apcatb.2011.08.012

[16] Wang, F., Min, S.X., Han, Y.Q. and Feng, L. (2010) Visible-Light-Induced Photocatalytic Degradation of Methylene Blue with Polyaniline-Sensitized $\mathrm{TiO}_{2}$ Composite Photocatalysts. Superlattices and Microstructures, 48, 170-180. http://dx.doi.org/10.1016/j.spmi.2010.06.009

[17] Galoppini, E. (2004) Linkers for Anchoring Sensitizers to Semiconductor Nanoparticles. Coordination Chemistry Reviews, 248, 1283-1297. http://dx.doi.org/10.1016/j.ccr.2004.03.016

[18] Choi, S.K., Yang, H.S., Kim, J.H. and Park, H. (2012) Organic Dye-Sensitized $\mathrm{TiO}_{2}$ as a Versatile Photocatalyst for Solar Hydrogen and Environmental Remediation. Applied Catalysis B, 121-122, 206-213.

[19] Johansson, E.M., Plogmaker, S., Walle, L.E., Schölin, R., Borg, A., Sandell, A. and Rensmo, H. (2010) Comparing Surface Binding of the Maleic Anhydride Anchor Group on Single Crystalline Anatase $\mathrm{TiO}_{2}(101)$, (100), and (001) Surfaces. Journal of Physical Chemistry C, 114, 15015-15020. http://dx.doi.org/10.1021/jp104897k

[20] Lopez, A., Bitzer, T., Heller, T. and Richardson, N.V. (2001) Adsorption of Maleic Anhydride on Si(100)-2 x 1. Surface Science, 477, 219-226. http://dx.doi.org/10.1016/S0039-6028(01)00775-0

[21] Bishop, L.M., Yeager, J.C., Chen, X., Wheeler, J.N., Torelli, M.D., Benson, M.C., Burke, S.D., Pedersen, J.A. and Hammers, R.J. (2012) A Citric Acid-Derived Ligand for Modular Functionalization of Metal Oxide Surface Via "Click" Chemistry. Langmuir, 28, 1322-1329. http://dx.doi.org/10.1021/la204145t

[22] Wilson, J.N., Titheridge, D.J., Kieu, L. and Idriss, H. (2000) Reactions of Maleic Anhydride Over TiO 2 (001) Single Crystal Surfaces. Journal of Vacuum Science \& Technology A, 18, 1887-1892. http://dx.doi.org/10.1116/1.582441

[23] Bates, S.P., Kresse, G. and Gillan, M.J. (1998) The Adsorption and Dissociation of ROH Molecules on TiO 2 (110). Surface Science, 409, 336-349. http://dx.doi.org/10.1016/S0039-6028(98)00278-7

[24] Gong, X.Q., Selloni, A., Batziull, M. and Diebold, U. (2006) Steps on Anatase $\mathrm{TiO}_{2}$ (101). Nature Materials, 5, 665670. http://dx.doi.org/10.1038/nmat1695

[25] Zeng, W., Liu, T., Wang, Z., Tsukimoto, S., Saito, M. and Ikuhara, Y. (2010) Oxygen Adsorption on Anatase TiO 2 (101) and (001) Surfaces from First Principles. Materials Transactions, 51, 171-175. http://dx.doi.org/10.2320/matertrans.M2009317

[26] Kavathekar, R.S., Dev, P., English, N.J. and MacElroy, J.M.D. (2011) Molecular Dynamics Study of Water in Contact with $\mathrm{TiO}_{2}$ Rutile-110, 100, 101, 001 and Anatase-101, 001 Surface. Molecular Physics, 109, 1649-1656. http://dx.doi.org/10.1080/00268976.2011.582051

[27] Cai, Y., Bai, Z., Chintalapati, S., Zeng, Q. and Feng, Y.P. (2013) Transition Metal Atoms Pathways on Rutile TiO 2 (110) Surface: Distribution of $\mathrm{Ti}^{3+}$ States and Evidence of Enhanced Peripheral Charge Accumulation. Journal of Chemical Physics, 138, 154711-1, 54711-14. 
[28] Girol, S.G., Strunskus, T., Muhler, M. and Woll, C. (2004) Reactivity of ZnO Surfaces toward Maleic Anhydride. Journal of Physical Chemistry B, 108, 13736-13745. http://dx.doi.org/10.1021/jp048386d

[29] Wilson, J.N. and Idriss, H. (2005) Reactions of Glutaric Acid on the $\mathrm{TiO}_{2}$ (001) Single Crystal. Effect of Surface Reduction on the Reaction Pathway. Langmuir, 21, 8263-8269. http://dx.doi.org/10.1021/la050951w

[30] Gao, Y.K. (2010) Probing the Interaction of Small Organic Molecules on Metal Oxide Surfaces. Ph.D. Thesis, Ruhr Universität Bochum Faculty of Chemistry Physical Chemistry 1, Bochum.

[31] Sprenger, D. and Anderson, O. (1991) Deconvolution of XPS Spectra. Fresenius' Journal of Analytical Chemistry, 341, 116-120. http://dx.doi.org/10.1007/BF00322120

[32] Ni, J., Meunier, F.C., Robles-Manuel, S., Barrault, J. and Valange, S. (2011) Characterization of Surface Acidity of Carbonated Materials by IR-Sensitive Molecular Probes: Advantages of Using Tert-Butyl Cyanide. Journal of Physical Chemistry C, 115, 24931-24936. http://dx.doi.org/10.1021/jp2085632

[33] Mirone, P. and Chiorboli, P. (1962) Infrared and Raman Spectra and Vibrational Assignment of Maleic Anhydride. Spectrochimica Acta, 18, 1425-1432.

[34] Parker, S.F., Wilson, C.C., Tomkinson, J., Keen, D.A., Shankland, K., Ramirez-Cuesta, A.J., Mitchell, P.C.H., Florence, A.J. and Shankland, N. (2001) Structure and Dynamics of Maleic Anhydride. Journal of Physical Chemistry A, 105, 3064-3070. http://dx.doi.org/10.1021/jp0038005

[35] Vogt, N., Demaison, J. and Rudolph, H.D. (2011) Equilibrium Structure and Spectroscopic Constants of Maleic Anhydride. Structural Chemistry, 22, 337-343. http://dx.doi.org/10.1007/s11224-010-9714-7

[36] Nijhuis, T., Visser, T. and Weckhuysen, B.M. (2005) The Role of Gold in Gold-Titania Epoxidation Catalysts. Angewandte Chemie International Edition, 44, 1115-1118. http://dx.doi.org/10.1002/anie.200462043

[37] Ruiz, A., Der Linden, B., Makkee, M. and Mul, G. (2009) Acrylate and Propoxy-Groups: Contributors to Deactivation of $\mathrm{Au} / \mathrm{TiO}_{2}$ in the Epoxidation of Propene. Journal of Catalysis, 266, 286-290. http://dx.doi.org/10.1016/j.jcat.2009.06.019

[38] Fang, W.Q., Gong, X. and Yang, H.G. (2011) On the Unusual Properties of Anatase $\mathrm{TiO}_{2}$ Exposed by Highly Reactive Facets. Journal of Physical Chemistry Letters, 2, 725-734. http://dx.doi.org/10.1021/jz200117r

[39] Vittadini, A., Selloni, A., Rotzinger, F.P. and Grätzel, M. (1998) Structure and Energetics of Water Adsorbed at TiO 2 Anatase (001) and (001) Surfaces. Physical Review Letters, 81, 2954-2957. http://dx.doi.org/10.1103/PhysRevLett.81.2954

[40] Kim, K.S. and Barteau, M.A. (1990) Structural Dependence of the Selectivity of Formic Acid Decomposition on Faceted Titania (001) Surfaces. Langmuir, 6, 1485-1488. http://dx.doi.org/10.1021/la00099a009

[41] Nikumbh, A., Pardeshi, K. and Raste, M.N. (2001) A Study of the Thermal Decomposition of Cooper (II) and Zinc (II) Malonate Maleate and Succinate Complexes Using Direct Current Electrical Conductivity Measurements. Thermochimica Acta, 374, 115-128. http://dx.doi.org/10.1016/S0040-6031(01)00483-X

[42] Feist, M., Kunze, R., Neubert, D., Witke, K., Mehner, H. and Kemnitz, E. (2000) Two Oxidation States and Four Different Coordinations of Iron in an Unusual Chloro Complex TG-MS, Raman and Mössbauer Spectroscopic Investigations of the Thermal Behavior. Thermochimica Acta, 361, 53-60. http://dx.doi.org/10.1016/S0040-6031(00)00546-3

[43] Wang, D.S., Zhang, J., Luo, Q.Z., Li, X.Y., Duan, Y.D. and An, J. (2009) Characterization and Photocatalytic Activity of Poly(3-Hexylthiophene)-Modified $\mathrm{TiO}_{2}$ for Degradation of Methyl Orange under Visible Light. Journal of Hazardous Materials, 169, 546-450. http://dx.doi.org/10.1016/j.jhazmat.2009.03.135

[44] Li, X.Y., Wang, D.S., Cheng, G.X., Luo, Q.Z., An, J. and Wang, Y.H. (2008) Preparation of Polyaniline-Modified $\mathrm{TiO}_{2}$ Nanoparticles and Their Photocatalytic Activity under Visible Light Illumination. Applied Catalysis B, 81, 267273. http://dx.doi.org/10.1016/j.apcatb.2007.12.022 
Scientific Research Publishing (SCIRP) is one of the largest Open Access journal publishers. It is currently publishing more than 200 open access, online, peer-reviewed journals covering a wide range of academic disciplines. SCIRP serves the worldwide academic communities and contributes to the progress and application of science with its publication.

Other selected journals from SCIRP are listed as below. Submit your manuscript to us via either submit@scirp.org or Online Submission Portal.
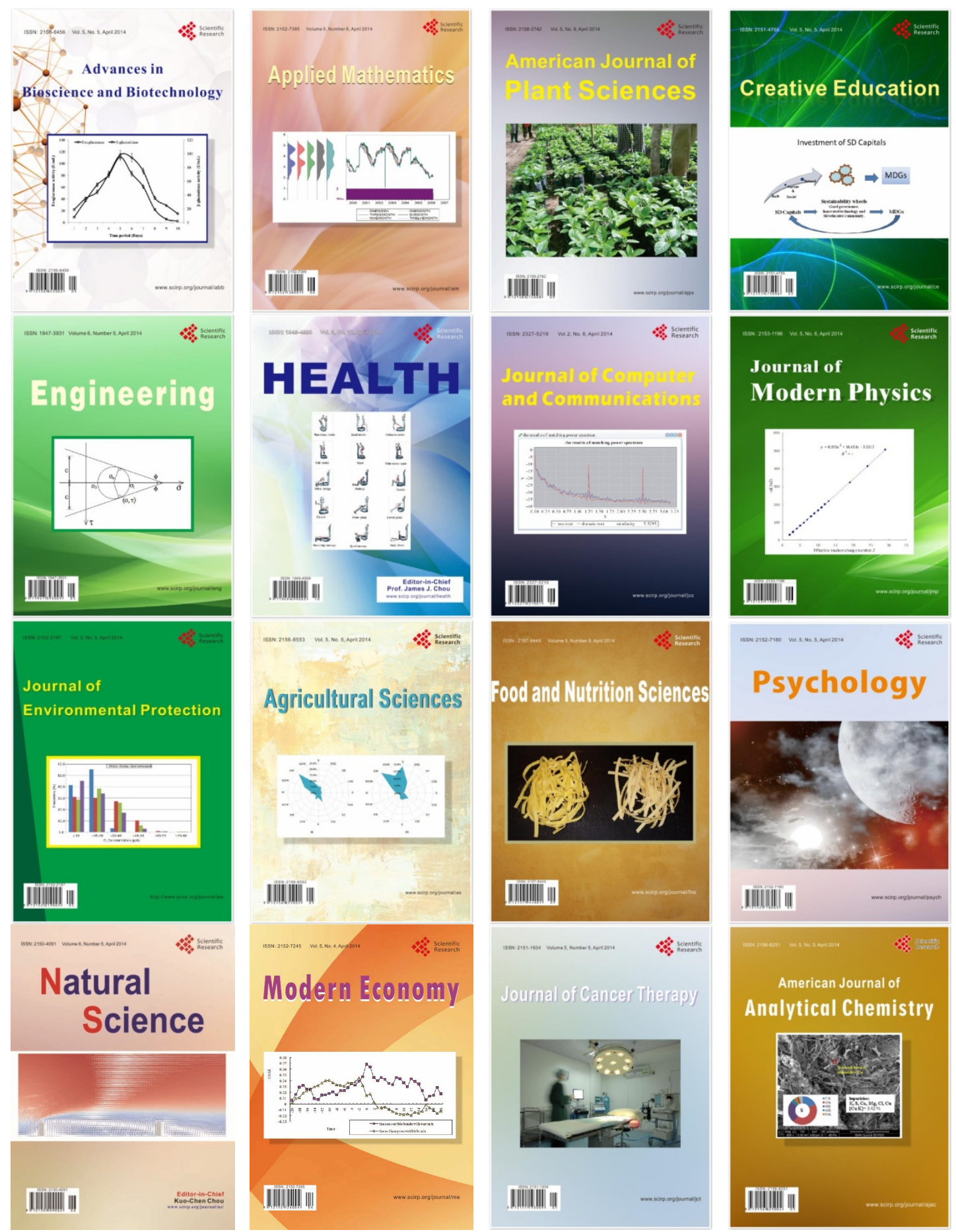